\title{
A new case of trisomy 5 with complex karyotype abnormalities in B-cell prolymphocytic leukemia: a case study
}

Musa Makongoro ${ }^{1 \dagger}$, Mahmoud Matar Mohammad Abu Rakhey ${ }^{1 \dagger}$, Yafei Yu' , Jianzhi Sun ${ }^{1}$, Guosheng Li ${ }^{1}, \mathrm{Na} \mathrm{He}^{1}$, Samir Ali Abd El-Kaream² and Daoxin Ma ${ }^{1 *+}$

\begin{abstract}
Background: The B-cell prolymphocytic leukemia (B-PLL) diagnosis is challenging due to the superposition with mature B-cell leukemia and/or lymphoma.

Objective: An insight case study of trisomy 5 with complex karyotype abnormalities in B-cell prolymphocytic leukemia.
\end{abstract}

Subject and methods: A 72-year-old man was referred to the Hematology Department, Qilu Hospital, Shandong University, because of persistent fever (10 days) and lymphocytosis. A detailed diagnostic methods including complete blood count, bone marrow aspiration, flow cytometry, conventional karyotype analysis, fluorescence in situ hybridization (FISH), quantitative real-time polymerase chain reaction (qRT-PCR), next-generation sequencing technology (NGS) used to detect 41 kinds of mutant genes related to hematological malignancies were conducted and reasonable therapeutic regimens including emergent leukapheresis accompanied by basification of urine and hydrotherapy, followed by a regimen of cyclophosphamide and dexamethasone.

Results: Subject white blood cell count was $143.43 \times 10^{9} / \mathrm{L}$, and $56 \%$ prolymphocytes. He did not show lymphadenopathy but splenomegaly. Immunophenotyping of prolymphocytes was CD5(+low), CD10(-), CD11C(-), CD19(+), CD20(+), cCD22(+), CD23(-), cCD79a(+), CD79b(+), FMC7( $)$, CD43(-), CD3(-), CD56(-), CD103(-), HLA-DR(+), and Lambda(+). R-banding and FISH revealed that leukemia cells carried extra chromosome 5. Considering the rare occurrence of trisomy 5 found in prolymphocytic leukemia, especially in Asians, with rapid disease progression. We know that median survival of B-PLL is three years after diagnosis, while survival time of this patient was only 1 month.

Conclusion: This study could provide the firsthand materials for precision, medicine and mechanism research in cytogenetics and molecular biology. It inferred that trisomy 5 might be a poor prognosis indicator, providing directions for clinical practice in the foreseeable future.

Keywords: B-cell prolymphocytic leukemia (B-PLL), Trisomy 5, Fluorescent in situ hybridization (FISH), Nextgeneration sequencing (NGS)

\footnotetext{
*Correspondence: daoxinma@sdu.edu.cn

${ }^{\dagger}$ Musa Makongoro, Mahmoud Matar Mohammad Abu Rakhey and

Daoxin Ma have contributed equally to this work

${ }^{1}$ Department of Hematology, Shandong University-Qilu Hospital, Jinan,

China

Full list of author information is available at the end of the article
}

\section{Introduction}

B-cell prolymphocytic leukemia (B-PLL) is an aggressive, out of control growth of B- lymphocyte cells with scarce neoplasm that represents $1 \%$ of lymphocytic leukemia and accompanied by a low survival rate. B-PLL was first described as a variant form of B-cell chronic lymphocytic leukemia (CLL) in the early 1970s [1-7], while it 
was implicated as an eminent clinic-pathologic entity and realized as a prolymphocytes malignancy influencing bone marrow (BM), blood, and spleen in the fourth edition of the 2008 World Health Organization (WHO) categorization [2-9]. 69 years is the mean age at diagnosis, with slightly male predominance. Patients typically exhibit B-symptoms, lymphocytosis, and splenomegaly, but lymphadenopathy is infrequent. It is considered by the WHO when more than $55 \%$ of the peripheral blood the lymphocytes are prolymphocytes, or when a lymph node or BM sample shows that prolymphocytes are the majority of lymphocytes. Molecular profiling and cytogenetic studies have failed to define and represent a single genetic aberration, instead abnormality of TP53/p53, deletion on 11q23, and/or 13q14, and trisomy 12 complex karyotypes have been documented. It is particularly worth mentioning that patient with karyotype abnormalities involving trisomy 5 is the first time to be reported in prolymphocytic leukemia [3-11].

\section{Case report}

A 72-year Chinese male was admitted to our Hematology Department, Qilu Hospital, Shandong University, with a history of 10-day fever, fatigue, poor appetite, diarrhea, and abdominal pain. His previous medical history showed that he had a chronic hepatitis B for almost 40 years and painless splenomegaly for about ten years. He was a peasant and had no reported exposure to environmental carcinogen. On the admission day, he presents a brief syncopal episode. Upon inspection, he had a $38.3^{\circ} \mathrm{C}$ temperature, conjunctiva and mucosal pallor was reported. The superficial lymph nodes were not palpable. About $7 \mathrm{~cm}$ below the left costal margin the spleen tip was palpable and confirmed through radiological investigations including: chest $\mathrm{x}$ ray, and abdominal ultrasound as conducted in previous studies and published leukemia diagnosis work $[6,10,12]$. Rest of the physical examinations was negative. The whole blood count revealed the white cell, hemoglobin, and platelet were $143.43 \times 10^{9} / \mathrm{L}$, $101 \mathrm{~g} / \mathrm{L}$, and $79 \times 10^{9} / \mathrm{L}$, respectively. The peripheral blood smear showed $87 \%$ of the nucleated cells were leukemic blasts with an elevated nuclear/cytoplasmic ratio, $56 \%$ of which were prolymphocytes with larger cell bodies and more prominent nucleoli. Renal and hepatic functions were normal. qRT-PCR displayed that serum level of Hepatitis B DNA and lactate dehydrogenase (LDH) was $1.25 \times 10^{3} \mathrm{IU} / \mathrm{mL}$ and $2014 \mathrm{U} / \mathrm{L}$ respectively, which was much higher than normal which could be also be related to post chemotherapy death. The current work was approved by Shandong University Research Ethical Committee, and written informed consent was obtained from participant family enrolled prior to sample collection.

\section{Morphology and immunology}

Bone marrow aspiration, smear and biopsy were carried out for morphological and immunological studies according to previous studies $[6,10-13]$. The bone marrow smear represented $100 \%$ cellularity, with $91 \%$ blasts infiltration. Sixty-five percent among them were prolymphocytes characterized by large cell bodies, and prominent nucleoli. The blasts exhibit a high ratio of nuclear versus cytoplasm. Auer rods were not present (Fig. 1). Flow cytometry showed the blasts expressed CD19, CD20, CD5 (low), CD79a, cCD22, cCD79a, HLA-DR, FMC7 (low), and Lambda, but did not express CD10, CD23, CD34, myeloperoxidase (MPO), cCD3 and Kappa. All results above revealed the patient with mature B-cell neoplasm, in which B-PLL, mantle cell lymphoma (MCL), a variant form of hairy cell leukemia (HCL-V) and splenic marginal zone lymphoma (SMZL) were highly suspicious types (Fig. 1).

\section{Cytogenetics}

Cells were cultured in penicillin $(100 \mathrm{U} / \mathrm{mL})$, streptomycin (100 fig $/ \mathrm{mL}$ ), and 10\% fetal calf serum (FCS) in the presence of TPA $(0.05 \mathrm{pg} / \mathrm{mL}$ final concentration) RPMI. Cells were harvested after 3 and 5 days of culture, and treated with hypotonic solution $(075 \mathrm{~mol} / \mathrm{L}, \mathrm{KCIO}$, $\left.10 \mathrm{~min}, 37^{\circ} \mathrm{C}\right)$ after $(0.1 \mathrm{pg} / \mathrm{mL}$ colcemid, $60 \mathrm{~min})$ mitotic arrest and with acetic acid/methanol (1:3) fixed. Metaphase chromosomes $\mathrm{G}$ banded were applied according to universal methods.

Fluorescence in situ hybridization (FISH) analysis: hypotonically fixed cells were placed drop-wise on slides and with fluorescent probes against $5 \mathrm{q}, 7 \mathrm{q}, 20 \mathrm{q} 12,+8$, $-\mathrm{Y}, \mathrm{RB1}, 1 \mathrm{q} 21, \mathrm{D} 13 \mathrm{~S} 319$ and IgH hybridized for $16 \mathrm{~h}$.

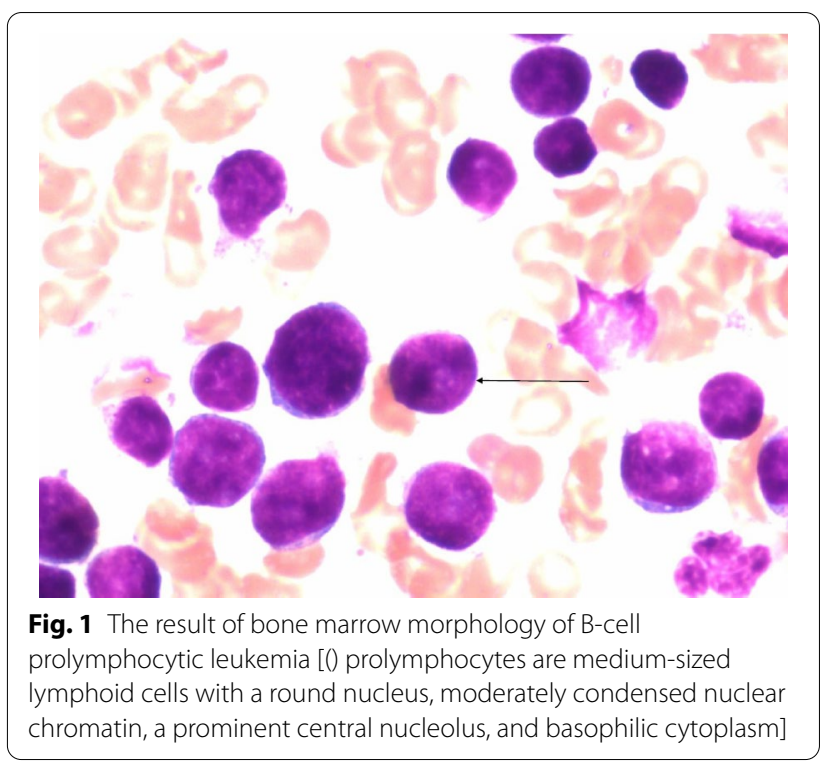


Under a fluorescence microscope cells were observed after staining with DAPI, the for fluorescence signals measurement. FISH was used to detect cytogenetic abnormalities. According to FISH results, three red, and three green fluorescent signals were observed by using two pairs of probes, CSF1R/D5S23, D5S7213(5q33) and EGR1/D5S23, D5S721(5q31), which were located in 5, that means it has an extra trisomy 5 (Fig. 2) and the detection of $\mathrm{t}(11 ; 14)$ (q13; q32) translocation by CCND1/IGH probe was negative. We also used other probes, which are located in 7q31, 20q12,+8, ATM (11q22.3), RB1 (13q14), D13S25 (13q14.3), P53 (17p13.1), IGH, D13S319, and $1 \mathrm{q} 21$ that associated with chromosomal changes of CLL, MM, and MDS, but there was no positive result. The Karyotype analysis was performed using a standard protocol. It revealed that $49, \mathrm{XY},+5, \operatorname{del}(5)(\mathrm{q} 13)$, add $(8)(\mathrm{p} 23),+15$, add(17)(q25),+19[cp20] (Fig. 3), which was the same as the FISH results (Figs. 2, 3).

\section{Molecular biology}

qRT-PCR was utilized to determine the molecular abnormality in bone marrow cells from the patient. However, we did not observe any positive result on 43 kinds of fusion genes detection, such as breakpoint cluster region/Abelsen (BCR/ABL), promyelocytic leukemia/retinotic acid receptor alpha (PML/RARA), a core-binding factor $\beta$ myosin heavy chain 11 (CBFB/ MYH11), acute myeloid leukemia 1/eight-twenty one (AML1/ETO), mixed-lineage leukemia (MLL) gene rearrangement (Table 1). Genomic material was extracted for targeted gene mutation panel by NGS technology. Bioinformatics and statistics were used to determine the association between clinical features and gene mutations also discuss of our results with the Cancer Genome Atlas Research Network (TCGA) public dataset. NGST was used to detect 41 kinds of mutant genes related to hematological malignancies, and the results showed mutation rates of SETBP1 and PML were $51.06 \%$ and $98.54 \%$ (Table 2). PCR determination of $\mathrm{B}$ cell clonal immunoglobulin gene rearrangements showed the positive result of B cell monoclonality.

\section{Treatment}

The patient of study was diagnosed with B-cell prolymphocytic leukemia. He underwent emergent leukapheresis accompanied by basification of urine and hydrotherapy. Then, we started on a regimen of cyclophosphamide and dexamethasone instead of fludarabine, considering the patient and his family conditions, including their poor economic incomes and the patient's age. After 10-day therapy, the patient attained slightly stable and improving conditions with normal temperature, significantly decreased white cell count and safe levels of hemoglobin and platelet. He left our hospital against medical advice without continuous supportive treatment, and observation. He died at the local hospital 11 days after leaving our hospital. The family declined an autopsy. No further studies can be performed due to the patient's death.

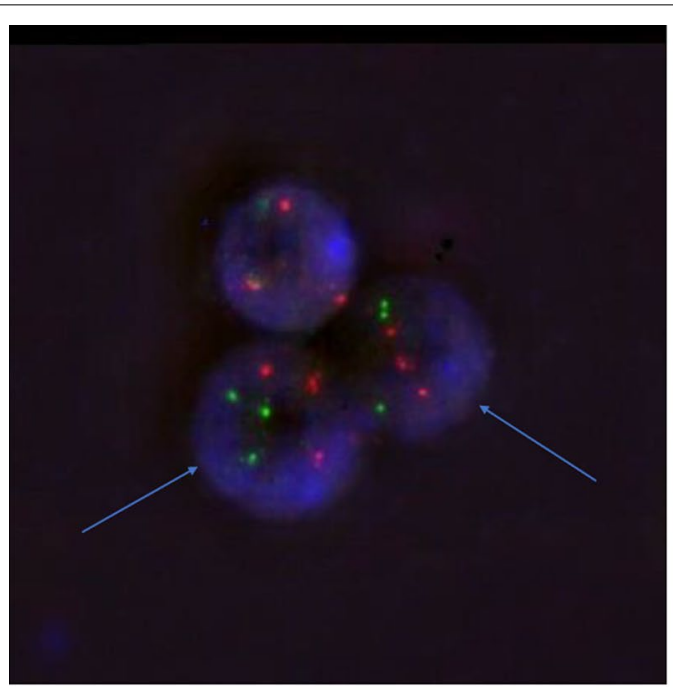

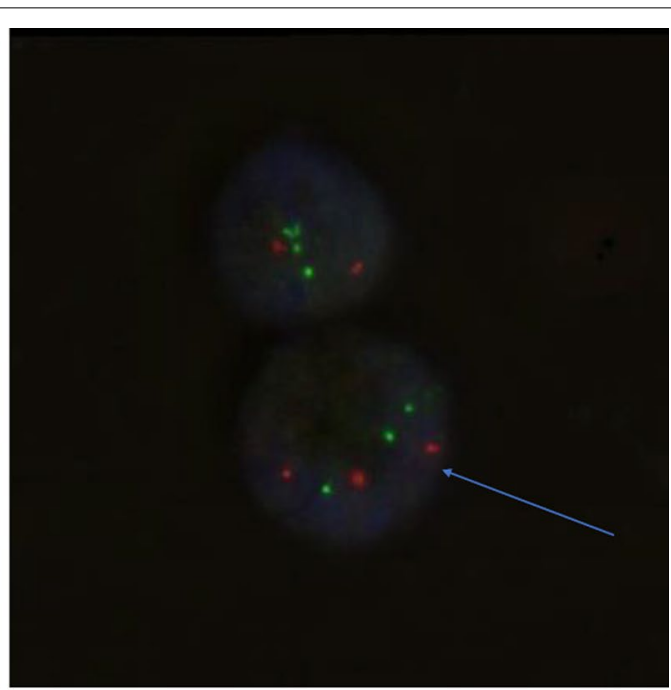

b

Fig. 2 The FISH analysis results with red (color) and green (color) probing of interphase B-cell prolymphocytic leukemia displaying a normal fusion signal and $\mathbf{b}$ split signal (arrow) red 5' centromeric region and (arrow) green $3^{\prime}$ telomeric region 


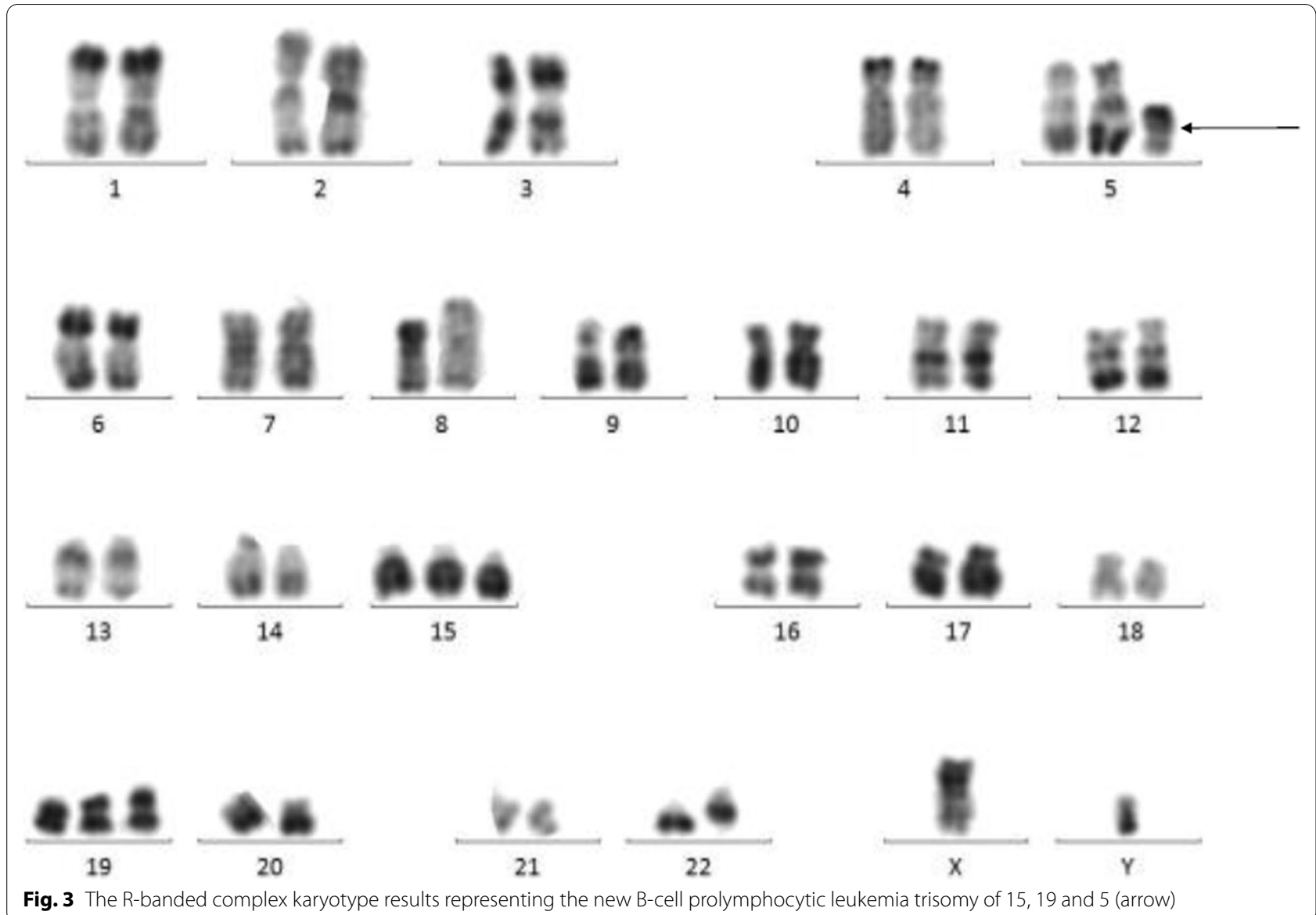

Table 1 The screening results of fusion genes detected with qRT-PCR method

\begin{tabular}{|c|c|c|c|c|c|c|c|}
\hline Fusion gene & Result & Fusion gene & Result & Fusion gene result & Result & Fusion gene & Result \\
\hline BCR-ABL & - & SIL-TAL1 & - & MLL-AF4 & - & FIP1L1-PDGFRA & - \\
\hline AML1-ETO & - & NPM-MLF1 & - & MLL-AF6 & - & ETV6-PDGFRA & - \\
\hline AML1-MDS1/EVI1 & - & NPM-ALK & - & MLL-AF9 & - & DEK-CAN & - \\
\hline AML1-MTG16 & - & CBFB-MYH11 & - & MLL-AF10 & - & SET-CAN & - \\
\hline PML-RARa & - & E2A-HLF & - & MLL-AF17 & - & NUP98-HoxA9 & - \\
\hline NPM-RARa & - & E2A-PBX1 & - & MLL-ELL & - & NUP98-HoxA11 & - \\
\hline FIP1L1-RARa & - & TLS-ERG & - & MLL-ENL & - & NUP98-HoxA13 & - \\
\hline PRKAR1A-RARa & - & TEL-JAK2 & - & MLL-AF1q & - & NUP98-HoxC11 & - \\
\hline NUMA1-RARa & - & TEL-AML1 & - & MLL-AF1p & - & NUP98-HoxD13 & - \\
\hline PLZF-RARa & - & TEL-ABL & - & MLL-AFX & - & NUP98-PMX1 & - \\
\hline STAT5b-RARa & - & TEL-PDGFRB & - & MLL-SEPT6 & - & & \\
\hline
\end{tabular}

"_" Means there was no positive result found

\section{Discussion}

We described a case of B-PLL carrying trisomy 5 with complex karyotype abnormalities, which was determined by conventional karyotype analysis and interphase/ metaphase FISH. It is known that the B-PLL diagnosis is challenging because of superposition with MCL,
HCL-V, or SMZL mature B-cell leukemia and lymphoma. The 72-year-old patient exhibited the typical features of B-PLL, lymphocytosis, splenomegaly, and B-symptoms. Though the patient was old, the results of morphology and immunology detection, as well as rapid and marked increase in the peripheral white cell count, were 
Table 2 The screening results of gene mutation detected by next-generation sequencing

\begin{tabular}{llllllll}
\hline Gene & Result & Gene & Result & Gene & Result & Gene & Result \\
\hline FLT3 & - & ASXL1 & - & SETBP1 & $51.06 \%^{\text {a }}$ & PML & WT1 \\
NPM1 & - & PHF6 & - & ETV6 & - & - & PTPN11 \\
KIT & - & TP53 & - & IKZF1 & - & CDKN2A \\
CEBPA & - & SF3B1 & - & PAX5 & CDKN2B & - \\
DNMT3A & - & SRSF2 & - & JAK1/JAK2 & - & NT5C2 & - \\
IDH1 & - & U2AF1 & - & CRLF2 & - & SMC1A & - \\
IDH2 & - & ZRSR2 & - & NOTCH1 & - & SMC3 & - \\
TET2 & - & NRAS & - & FBXW7 & - & STAG2 \\
EZH2 & - & CBL & - & PTEN & - & - \\
FAM5C & - & RUNX1 & - & CREBBP & - & RAD21 \\
\hline
\end{tabular}

"_"Means there was no positive result found

${ }^{\text {a }}$ Percentage means the mutant proportion of mutant gene in detected samples

observed, which were both different from the features of CLL. The diagnosis requirements of more than $55 \%$ of the lymphocytes in the peripheral blood are prolymphocytes, medium-sized cells with prominent central clumped chromatin nucleoli, and typical immune-phenotype, the expression of the B-cell antigens CD19, 20, 22 and 79a were present $[8,9]$. Moreover, the absence of $t(11 ; 14)$ (q13;q32) helped exclude MCL. Smooth outline of the blast cells, B-symptoms, higher WBC $\left(>100 \times 10^{9} / \mathrm{L}\right)$, and clinical course much more attributes of B-PLL compared to HCL-V or SMZL. Research in sixty subjects showed that splenomegaly was the most prevalent feature of B-PLL [7]. However, the molecular pathogenesis of B-PLL is still largely unknown. As for studies reported, complex karyotype and abnormalities in the TP53 tumor suppressor gene might be common events in B-cell PLL [9-12]. Moreover, deletions at 11q23, 13q14, and trisomy (especially 12) were found [11, 14-17]. A few case studies have reported transformed B-PLL and CLL, MYC translocations, including $\mathrm{t}(8 ; 14)[11,12,16-18]$.

Because gene fusions are crucial factors for risk stratification in leukemia risk-adapted therapy, gene fusion is indispensable diagnostic testing part. In the present work, fusion gene panels and clinical utility were analyzed based on targeted NGS for leukemia diagnosis. 41 kinds of mutant genes related to hematological malignancies, and the results showed mutation rates of SETBP1 and PML were 51.06\% and 98.54\% (Table 2). PCR determination of B cell clonal immunoglobulin gene rearrangements showed the positive result of $\mathrm{B}$ cell monoclonality $[19,20]$.

Unfortunately, we did not carry on an optimal individualized treatment regimen considering his economic income and their wishes. However, the choice of personalized treatment regimen is always the critical point in research of hematological disorders. A study on four patients with PLL was carried out, whose age ranged between 55 and 84 years, with the leucocyte count above $180 / \mathrm{nL}, \beta 2$-microglobulin and $\mathrm{LDH}$ higher with a median of $4.2 \mathrm{mg} / \mathrm{L}$ and $284 \mathrm{U} / \mathrm{L}$, respectively. The results showed that 4 patients achieved a complete remission with immune-chemotherapy fludarabine, epirubicin, and rituximab (FER regimen). It provided an impetus for further evaluation of the treatment schedule offered in a larger number of PLL patients [16-21]. Previous reports report the successful B-PLL treatment with monotherapy rituximab, while the durability responses were short [16-22]. All in all, integration of rituximab together with bendamustine or fludarabine with epirubicin or mitoxantrone (FER, BMR, and FMR) as anthracycline has been showed to be efficient in B-PLL [16, 22-26]. Some experts suggest that to patients with no TP53 abnormalities the usual approach is applying this regimen as cornerstone therapy. Alemtuzumab is vital in the treatment for B-PLL patients with mutations and/or deletions of TP53. Also, antagonists targeting molecules for the B-cell receptor as PI3 Kinase delta (PI3Kd) and Burton's Tyrosine Kinase, may also have efficacy in B-PLL, including TP53 abnormalities cases. However, ofatumumab, GA101, or new anti-CD20 mAbs have not been assessed in B-PLL. Recent researches revealed that idelalisib, a powerful oral and selective PI3Kd inhibitor, combined with rituximab responses was found to be clinically meaningful and rapid in B-PLL patients with disrupted TP53 [21-27]. Also, Gordon et al. stated that two B-PLL patients, with $\operatorname{del}(17 \mathrm{p})$, responded to ibrutinib single therapy, an oral inhibitor of Burton's tyrosine kinase, involved in signal transduction of B-cell receptor. Two patients treated with ibrutinib for months reached normal absolute count of lymphocyte, hemoglobin and platelet [26-36]. At last, the only therapeutic approach 
in B-PLL and should be taken into account for younger subjects remain the allogeneic hematopoietic stem cell transplant (allo-HSCT).

\section{Conclusion}

In conclusion, complex karyotypic abnormalities and aberrations in TP53 probably indicated the B-PLL poor prognosis. Even deficiency of efficient established therapeutic modalities, FMR, FER, BMR, alemtuzumab, idelalisib-rituximab and ibrutinib all exhibited remarkable effect on therapy of B-PLL patients. Taking the cost of treatment into account, more economical and effective regimens should be researched to make sure that patients can afford them. Further molecular profiling and cytogenetic studies remain to be performed to define genetic aberration clearly, such as trisomy 5 . While we did not demonstrate the role of trisomy 5 on B-PLL, we put emphasis on specific cytogenetic and molecular abnormalities, which could promote the deep-going research in the field of B-PLL.

\begin{abstract}
Abbreviations
B-PLL: B-cell prolymphocytic leukemia; FISH: Fluorescence in situ hybridization; qRT-PCR: Quantitative real-time polymerase chain reaction; NGS: Next-generation sequencing; CLL: Chronic lymphocytic leukemia; BM: Bone marrow; LDH: Lactate dehydrogenase; BCR/ABL: Breakpoint cluster region/ Abelsen; PML/RARA: Promyelocytic leukemia/retinotic acid receptor alpha; CBFB/MYH11: Core-binding factor $\beta$ myosin heavy chain 11; AML1/ETO: Acute myeloid leukemia 1/eight-twenty one; MLL: Mixed-lineage leukemia; WHO: World Health Organization.
\end{abstract}

\section{Acknowledgements}

All authors would like to thank patient family for participating in this report.

\section{Authors contributions}

MM, MM MAR, YY, JS, GL, NH, SAAEK, DM are shared in designing the research report, processing the samples, interpretation the patient data regarding the hematological disease and writing the case report and read and approved the final manuscript. All authors equally contributed.

\section{Funding}

This research did not receive any specific grant from funding agencies in the public, commercial, or not-for-profit sectors.

\section{Availability of data and materials}

Data and materials are available upon request.

\section{Declarations}

Ethics approval and consent to participate

The research methodology in the present work was approved by research ethical committee of Shandong University, and written informed consent was obtained from participant family enrolled in the case report prior to sample collection. Experimental procedures and sampling followed the international and national regulations in accordance with the Declaration of Helsinki.

\section{Consent for publication}

The authors grant the publisher permission to publish this work.

\section{Competing interests}

All authors declare that they have no competing interests.

\section{Author details}

${ }^{1}$ Department of Hematology, Shandong University-Qilu Hospital, Jinan, China. ${ }^{2}$ Department of Applied Medical Chemistry, Alexandria University-Medical Research Institute, Alexandria, Egypt.

Received: 27 October 2021 Accepted: 9 February 2022

Published online: 03 March 2022

\section{References}

1. Swerdlow SH, Campo E, Harris NL (eds) (2017) WHO classification of tumours of haematopoietic and lymphoid tissues, 4th edn. IARC Press, Lyon

2. Melo JV, Catovsky D, Galton DA (1986) The relationship between chronic lymphatic leukemia and prolymphocytic leukaemia, I: clinical and laboratory features of 300 patients and characterization of an intermediate group. Br J Haematol 63(2):377-387

3. Dearden C (2012) How I treat prolymphocytic leukemia. Blood 120(3):538-551

4. Dearden C (2015) Management of prolymphocytic leukemia. Hematol Am Soc Hematol Educ Program 2015:361-367

5. Collignon A, Wanquet A, Maitre E (2017) Prolymphocytic leukemia: new insights in diagnosis and in treatment. Curr Oncol Rep 19(4):29

6. El-Kaream SAA, Ebied SAEM, Sadek NA, Attia KAH, Nadwan EA (2021) Serum estrogen and its soluble receptor levels in Egyptian patients with chronic myeloid leukemia: a case-control study. Indian J Hematol Blood Transfus. https://doi.org/10.1007/s12288-021-01451-8

7. Cross M, Dearden C (2019) B and T cell prolymphocytic leukemia. Best Pract Res Clin Haematol 32(3):217-228

8. Wandt H, Haferlach T, Thiede C et al (2010) WHO classification of myeloid neoplasms and leukemia. Blood 115(748-9):749-750

9. Pittman S, Catovsky D (1983) Chromosome abnormalities in B-cell prolymphocytic leukemia: a study of nine cases. Cancer Genet Cytogenet 9:355-365

10. Ebied SAE, Sadek NA, Zaki NES, Abd El-Kaream SA, El Kashif HKA (2018) Prognostic value of soluble angiotensin II receptor 1 and soluble angiotensin converting enzyme [CD 143] in patients with acute leukemia. Acta Haematol Pol 49(4):240-250. https://doi.org/10.2478/ahp-2018-0028

11. Bindra BS, Kaur H, Portillo S, Emiloju O, Garcia de Jesus K (2019) B-cell prolymphocytic leukemia: case report and challenges on a diagnostic and therapeutic forefront. Cureus 11:e5629

12. El-Kaream SAA, Ebied SAEM, Sadek NA, Saad DM, Nadwan EA (2021) Serum estrogen and its soluble receptor levels in Egyptian patients with acute leukemia: case-control study. Egypt J Med Hum Genet 22:68. https://doi.org/10.1186/s43042-021-00186-5

13. Helaly NA, Esheba NE, Ammo DEA, Elwan NM, Elkholy RA (2021) High $\mathrm{Bax} / \mathrm{BCl}-2$ ratio is associated with good prognosis and better survival in patients with B cell chronic lymphocytic leukemia. Leuk Res 107:106604

14. Lens D, De Schouwer PJ, Hamoudi RA (1997) p53 abnormalities in B-cell prolymphocytic leukemia. Blood 89:2015-2023

15. Lens D, Matutes E, Catovsky D (2000) Frequent deletions at $11 q 23$ and 13 q14 in B cell prolymphocytic leukemia (B-PLL). Leukemia 14:427-430

16. Flatley $\mathrm{E}$, Chen Al, Zhao X (2014) Aberrations of MYC are a common event in B-cell prolymphocytic leukemia. Am J Clin Pathol 142(3):347-354

17. Put N, Van Roosbroeck K, Konings P (2012) Chronic lymphocytic leukemia and prolymphocytic leukemia with MYC translocations: a subgroup with an aggressive disease course. Ann Hematol 91:863-873

18. Huh YO, Lin KI, Vega F (2008) MYC translocation in chronic lymphocytic leukaemia is associated with increased prolymphocytes and a poor prognosis. Br J Haematol 142:36-44

19. Kim B, Kim E, Lee ST, Cheong JW, Lyu CJ, Min YH et al (2020) Detection of recurrent, rare, and novel gene fusions in patients with acute leukemia using next-generation sequencing approaches. Hematol Oncol 38(1):82-88. https://doi.org/10.1002/hon.2709

20. Engvall M, Cahill N, Jonsson Bl, Höglund M, Hallböök H, Cavelier L et al (2020) Detection of leukemia gene fusions by targeted RNA-sequencing in routine diagnostics. BMC Med Genomics 13:106. https://doi.org/10. 1186/s12920-020-00739-4

21. Merchant S, Schlette E, Sanger W (2003) Mature B-cell leukemias with more than $55 \%$ prolymphocytes: report of 2 cases with Burkitt 
lymphoma-type chromosomal translocations involving c-myc. Arch Pathol Lab Med 127:305-309

22. Lens D, Coignet LJ, Brito-Babapulle V (1999) B cell prolymphocytic leukaemia (B-PLL) with complex karyotype and concurrent abnormalities of the p53 and c-MYC gene. Leukemia 13:873-876

23. Chow KU, Kim SZ, von Neuhoff N (2011) Clinical efficacy of immunochemotherapy with fludarabine, epirubicin and rituximab in the treatment for chronic lymphocytic leukaemia and prolymphocytic leukaemia. Eur J Haematol 87(5):426-433

24. Mourad YA, Taher A, Chehal A, Shamseddine A (2004) Successful treatment of B-cell prolymphocytic leukemia with monocloncal anti-CD20 antibody. Ann Hematol 83(5):319-321

25. Perz J, Topaly J, Fruehauf S (2002) Level of CD20-expression and efficacy of rituximab treatment in patients with resistant or relapsing B-cell prolymphocytic leukemia or B-cell chronic lymphocytic leukemia. Leuk Lymphoma 43(1):149-151

26. Tempescul A, Feuerbach J, lanotto J-C (2009) A combination therapy with fludarabine, mitoxantrone and rituximab induces complete immunophenotypical remission in B-cell prolymphocytic leukaemia. Ann Hematol 88(1):85-88

27. Weide R, Pandorf A, Heymanns J, Koppler H (2004) Bendamustine/Mitoxantrone/Rituximab (BMR): a very effective, well toleroutpatient chemoimmunotherapy for relapsed and refractory CD20-positive indolent malignancies: final results of a pilot study. Leuk Lymphoma 45(12):2445-2449

28. Eyre TA, Fox CP, Shankara P. Idelalisib-Rituximab induces clinical remissions in patients with TP53 disrupted B cell prolymphocytic leukaemia. Br J Haematol. 2016.

29. Gordon MJ, Raess PW, Young K. Ibrutinib is an effective treatment for B-cell prolymphocytic leukaemia. Br J Haematol. 2016.

30. Chapiro E, Pramil E, Diop M (2019) Genetic characterization of B-cell prolymphocytic leukemia: a prognostic model involving MYC and TP53. Blood 134:1821-1831

31. Kay NE, Hanson CA (2019) B-cell prolymphocytic leukemia has 3 subsets. Blood 134:1777-1778

32. Hew J, Pham D, Matthews Hew T, Minocha V (2018) A novel treatment with obinutuzumab-chlorambucil in a patient with B-cell prolymphocytic leukemia: a case report and review of the literature. J Investig Med High Impact Case Rep 6:2324709618788674

33. George P, Brown A, Weinkove R (2020) B-cell prolymphocytic leukaemia with at $(4 ; 14)$ FGFR3/IGH translocation: response to ibrutinib. Pathology 52(4):491-492. https://doi.org/10.1016/.jpathol.2020.03.005

34. Moore J, Baran AM, Meacham PJ, Evans AG, Barr PM (2020) Initial treatment of B-cell prolymphocytic leukemia with ibrutinib. Am J Hematol 95(5):E108-E110. https://doi.org/10.1002/ajh.25733

35. Jain A, Khunger JM, Prasad P, Chaudhry S, Sharma M, Gupta DK, Saluja S (2020) An illustrative case of B-cell prolymphocytic leukemia. Blood Res 55:175-189

36. Bell S, Lattanzio N, Braham J, Campdesuner V, Abdelal Q, Vartanov A et al (2021) An unusual case of prolymphocytic leukemia transformation in a patient with chronic lymphocytic leukemia. J Investig Med High Impact Case Rep. https://doi.org/10.1177/2324709621990767

\section{Publisher's Note}

Springer Nature remains neutral with regard to jurisdictional claims in published maps and institutional affiliations.

\section{Submit your manuscript to a SpringerOpen ${ }^{\circ}$ journal and benefit from:}

- Convenient online submission

- Rigorous peer review

- Open access: articles freely available online

- High visibility within the field

- Retaining the copyright to your article

Submit your next manuscript at $\boldsymbol{\nabla}$ springeropen.com 